International Review of Research in Open and Distributed Learning Volume 16, Number 6

November - 2015

\title{
Comparing MOOC Adoption Strategies in Europe: Results from the HOME Project Survey
}
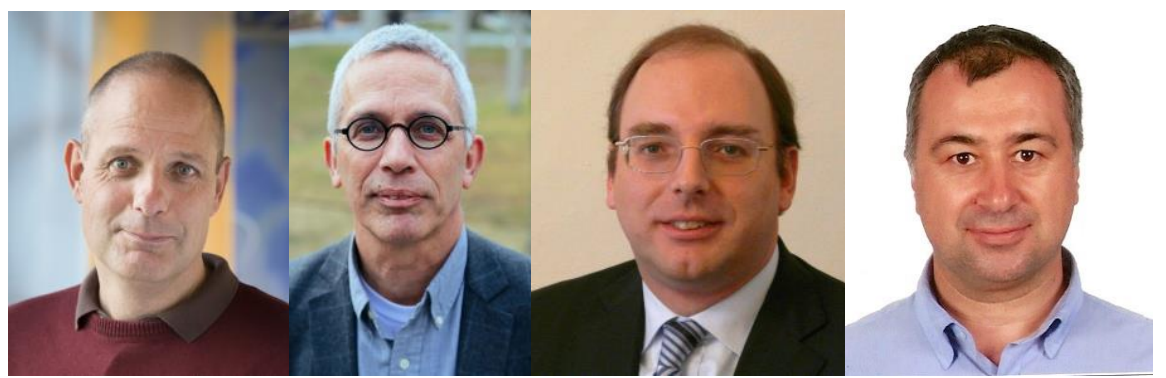

Darco Jansen ${ }^{1}$, Robert Schuwer ${ }^{2}$, Antonio Teixeira ${ }^{3}$, and Cengiz Hakan Aydin 4 ${ }^{1}$ EADTU, Netherlands, ${ }^{2}$ Fontys University of Applied Sciences, Netherlands, ${ }^{3}$ Universidade Aberta, Portugal, ${ }^{4}$ Anadolu University, Turkey

\begin{abstract}
Much of the literature and the academic discussion about institutional strategic planning of Massive Open Online Courses (MOOC) has been centred on the U.S. context. Literature on MOOCs in Europe is still developing and just recently some empirical studies were conducted. However, these studies are not comparable, and it is hard to learn about differences between regions and types of educational institutions. Given the very different institutional, political and cultural contexts, it is interesting to analyse how in these two different regions Higher Education institutions (HEIs) are responding to the challenges of the MOOC phenomena and are integrating it in their own strategic planning. The current research presents the first attempt to conduct a comparative study of institutional MOOC strategies in Europe and U.S. It is based on a survey launched by the EU-funded HOME project and compares results with a similar survey conducted in U.S. Results show that there are significant differences in how the U.S. and European HEIs understand the impact of massive open education and also how they perceive the efficiency of digital education and online learning.
\end{abstract}

Keywords: MOOC, Institution, Strategy, Higher Education, Survey, Open Education, Online Learning 


\section{Introduction}

The acronym MOOC was first coined in 2008 by Dave Cormier and Brian Alexander (Corner, 2008) at the CCKo8 conference led by George Siemens and Stephen Downes. Massive Open Online Courses (MOOCs) have received considerable media coverage since the beginning of 2012 and their rise to prominence was to a large extent driven by service providers such as Udacity, Coursera and edX. In 2013, MOOC activity began in earnest in Europe starting with the panEuropean initiative OpenupEd, and different (regional) MOOC platforms became available (e.g., FutureLearn, Iversity, FUN, UNEDcoma, Miríada X).

In September 2013, the European Commission launched the initiative Opening Up Education to further enhance the adoption of open education in Europe (European Commission, 2013). Recently the European Commission funded a number of MOOC projects. One of those projects, entitled as Higher Education Online: MOOCs the European way (HOME, 2014) intends to develop and strengthen an open network for European cooperation on open education and MOOCs. This is an ongoing project launched in 2014 and will be finalized in 2016.

It is observed from available data (Open Education Europa, 2015) that EU MOOC activities are mainly concentrated in Western Europe, serve a limited number of language communities, and have been mainly driven by individual ambitious players from the higher education (HE) sector. Although European higher education institutions (HEIs) are aware of the importance of MOOCs as a global movement and an instrument for educational policy, many have been hesitant to adopt or engage with MOOCs. It is indicated (e.g., Yuan, Powell, \& Olivier, 2014) that pedagogical issues, strategic and cost questions are among the concerns that have delayed European HEIs from entering into this movement.

However, the literature on MOOCs in Europe is still developing and lacks comprehensive studies, except the one just recently conducted by the European Universities Association (EUA) (Gaebel, Kupriyanova, Morais, \& Colucci, 2014). Meanwhile, as part of the HOME project, a survey study was conducted to contribute to the literature by providing an insight about European perspectives on MOOCs, to gain a better understanding of the strategic reasons why a higher education institution is or isn't involved in MOOCs, and to compare these reasons with the results of similar studies in U.S. (Allen \& Seaman 2014, 2015). The following parts of this manuscript cover the details of this study including the methodology, results and their interpretations, as well as a discussion of the importance of the different aspects associated with each letter of the MOOC acronym.

This work is licensed under a Creative Commons Attribution 4.0 International License. 


\section{Methodology}

Already for twelve successive years the Babson Group reports about the state of distance education and online learning in US higher education. Since 2013 they included a section dedicated to MOOCs (Allen \& Seaman 2014, 2015). In Europe such a comparable study is missing, let alone during such a long period. This survey study can be considered as a starting point to compare the strategy of European HEIs to MOOCs and to compare those strategies with the US institutions' strategies.

In the remainder of this article we will refer to our study as EU2014. We will compare the results with those of Allen and Seaman (2014, 2015) and the EUA (Gaebel et al., 2014). These surveys will be referenced to as US2013, US2014 and EUA2013 respectively.

\section{Instrumentation}

An online survey instrument was used to collect data from the European HEIs. In order to have a base to compare the results of this study with the Babson Group's results, quite a number of questions were adapted from the instrument Babson Group used. Additionally, several open and closed questions were added to the survey. For the closed questions, a five-point Likert scale type alternatives, ranging from "Not at all relevant for my institution" to "Highly relevant for my institution," was used. The survey consisted of the following 10 sections (exact wording as in the survey):

1. Profile Information (seven open questions)

2. How important are the following dimensions of a MOOC for the learners/participants? (16 closed questions)

3. Status of MOOC offerings at your institution (one closed question identical to the U.S. survey by Allen and Seaman, 2014)

4. Do you agree with the following statements? (four identical questions as used in the U.S. surveys and one open question)

5. Primary objective for your institution's MOOCs (one question with nine options identical to U.S. surveys)

6. Relative importance of the following objectives for your institution's MOOCs (four closed question plus one open question)

7. What are the primary reasons for your institution to collaborate with others on MOOCs? (three open questions)

This work is licensed under a Creative Commons Attribution 4.0 International License. 
8. How important are the following macro-drivers for your institutional MOOC offerings? (10 closed questions)

9. How important are the following macro-drivers for an active governmental involvement on MOOCs

(10 closed questions)

10. What are the primary reasons why your government is or isn't involved in MOOCs? (one open question)

This article discusses the results of sections one to six. The complete survey results are presented in a separate report (Jansen \& Schuwer, 2015).

Table 1 summarizes the main characteristics of the survey compared to the US2013, US2014 and EUA2013 surveys. The main difference is that the other surveys are self-selected while EU2014 was open to every European HEI. In general, the HEIs in the EU2014 survey were approached using newsletters and social media to complete the questionnaire. In addition, EU2014 was about MOOCs only while the other surveys focussed on e-learning and online learning.

All studies are biased to some extent. The US surveys (US2013 and US2014) are biased to the large institutions while EAU2013 is biased in favour of EUA member institutions involved in elearning. EU2014 seems to be biased to those countries and those institutions interested in MOOCs. To counteract for this bias, we report the results of the HEIs already offering a MOOC next to the results of all respondents (referenced to "EU2014 (MOOC offering)" in results below). As such the results of HEIs that have published a MOOC or are intended to, are comparable to the group of the US surveys as only those US institution that had MOOC offering or plans replied to their MOOC questions (see last column in Table 1).

Table 1

Survey Characteristics of Different MOOC Studies

\begin{tabular}{lllll}
\hline Survey & $\begin{array}{l}\text { Sample } \\
\text { methodology }\end{array}$ & $\begin{array}{l}\text { Total } \\
\text { sample }\end{array}$ & $\begin{array}{l}\text { Institutions } \\
\text { Responded }\end{array}$ & $\begin{array}{l}\text { Institutions answering } \\
\text { MOOC questions }\end{array}$ \\
US2013 & $\begin{array}{l}\text { Self-selected } \\
\text { sample }\end{array}$ & 4.726 in U.S. & 2.831 & $\begin{array}{l}\text { Only institutions that } \\
\text { had MOOC offering or } \\
\text { plans: } 405 \text { institutions } \\
(14.3 \%)\end{array}$ \\
& $\begin{array}{l}\text { Self-selected } \\
\text { sample }\end{array}$ & 4.891 in U.S. 2.807 & $\begin{array}{l}\text { Only institutions that } \\
\text { had MOOC offering or } \\
\text { plans: } 382 \text { institutions } \\
(13.6 \%)\end{array}$
\end{tabular}

This work is licensed under a Creative Commons Attribution 4.0 International License. 


$\begin{array}{lllll}\text { EUA2013 } & \begin{array}{l}\text { Self-selected } \\ \text { sample (EUA } \\ \text { members) }\end{array} & \begin{array}{l}\text { 80o in } \\ \text { Bologna } \\ \text { Area }\end{array} & \text { All 249 } \\ \text { EU2014 } & \text { Open } & \begin{array}{l}\text { Potentially } \\ \text { all HEIs in } \\ \text { European } \\ \text { system }\end{array} & \text { All 67 } \\ & & & \\ & & \end{array}$

All surveys ask institutions about MOOCs without providing a definition. Hence, institutions themselves can decide if their online course is a MOOC. This might introduce a bias. However, even specialists don't agree about the definition of a MOOC. Some argue that MOOCs do not have to be for free (Selwyn, Bulfin \& Pangrazio, 2015) or that a self-paced course cannot be a MOOC (Open Education Europa, 2014). To be comparable, this study did not define MOOC as well. However, the survey included several questions on the perceived importance of the different dimensions associated with each letter of the acronym MOOC.

\section{Participants}

In total 67 responses were obtained from HEIs of 22 European countries (EU and wider Europe). For example, we included Armenia and the Russian Federation as they are part of Bologna Area. This approach is consistent with EUA2013. Figure 1 illustrates the origin of the responses in the EU2014 survey. According to the European MOOC Scoreboard (Open Education Europa, 2014) there is a clear domination of Western and Southern countries with hardly any MOOC coming from Eastern Europe. As such the response largely matches with those countries most active in MOOCs. 

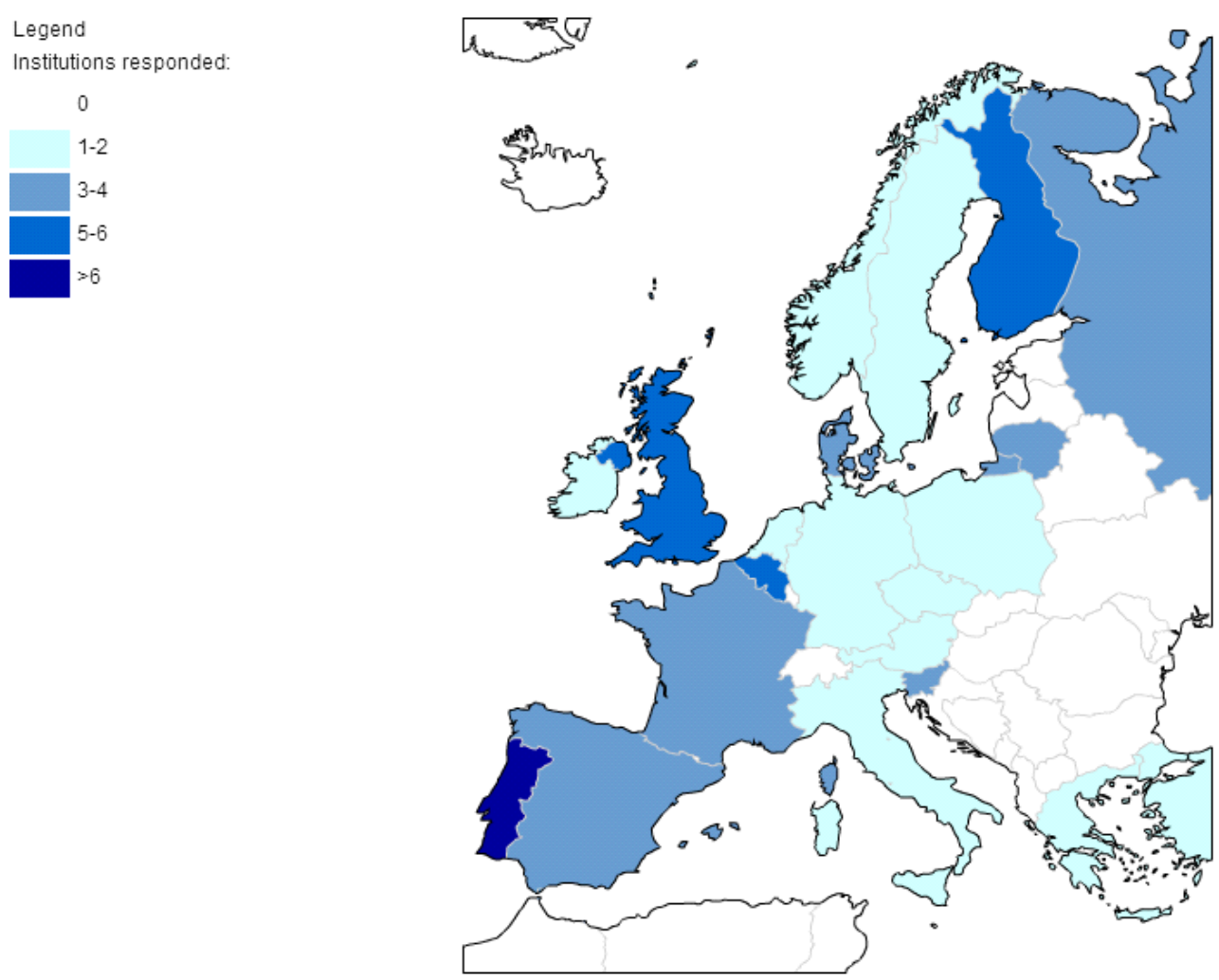

Figure 1. Geographical distribution of institutions responded.

\section{Process}

The study was conducted during the fourth quarter of 2014. The survey was developed during the summer of 2014 and tested among HOME partners. The online survey was open from 20 October to 19 December 2014.

\section{Results and Discussion}

In Figure 2 the institutional profile in MOOC offering in this survey (EU2014) is compared to that of US2013 and US2014. 


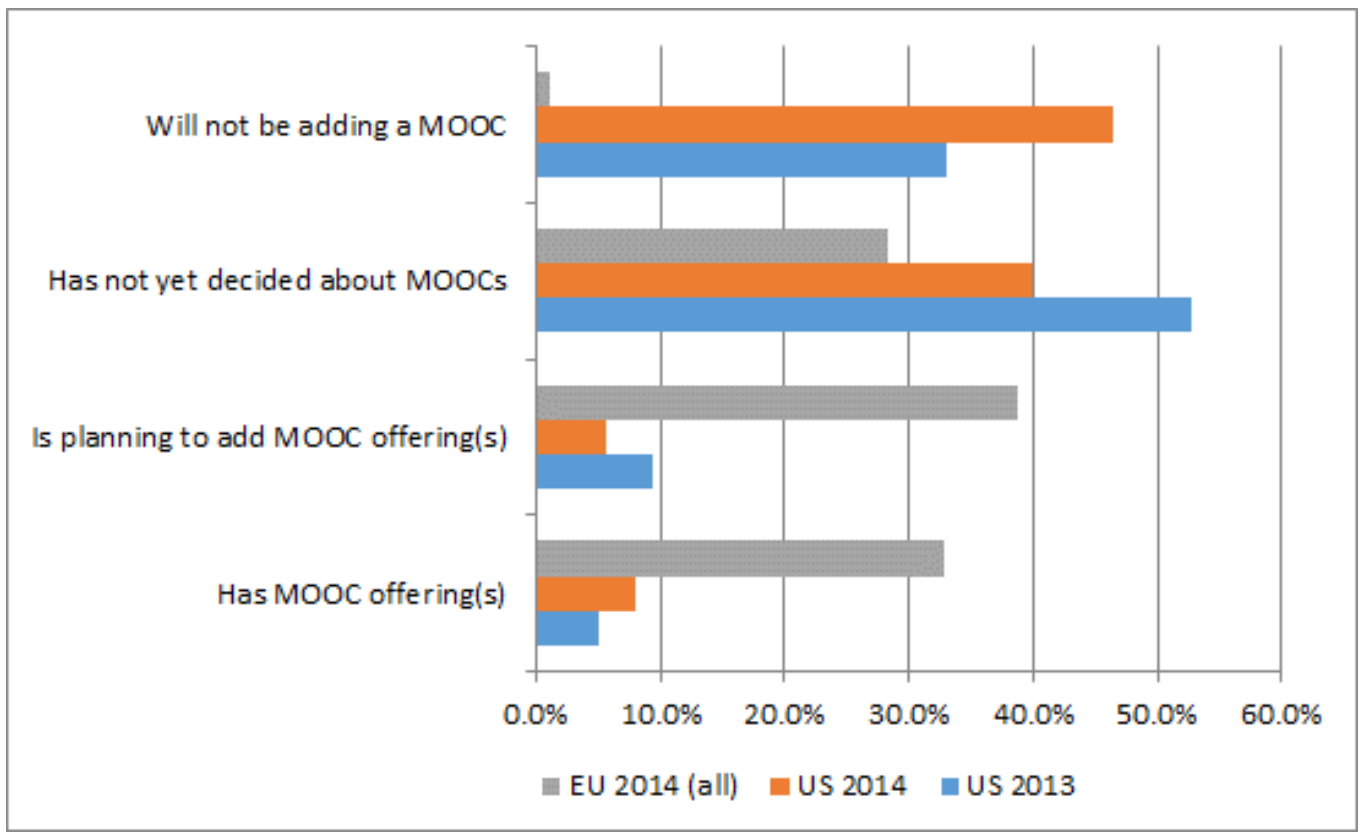

Figure 2. Institutional profile in MOOC offering.

In total $71.7 \%$ of the institutions has a MOOC or is planning to develop one. We might conclude that the European institutions are more involved in MOOCs compared to U.S. This can already be concluded out of the EUA2013 survey that was conducted in the same period as US2013. EUA2013 reports that 58\% of institutions offer planning to offer a MOOC against $14.3 \%$ in US2013 survey. Our study seems to confirm the EUA statement that "interest in MOOCs has far from peaked in Europe" (Gaebel et al. 2014, p.54).

The difference with the US is striking, although both the EUA2013 and this study might be biased in favour of HEIs involved in e-learning and MOOCs, respectively. However, another study (JRCIPTS, 2015) conducted in five large European countries confirms that many European HEIs offer MOOCs or plan to offer a MOOC soon. Their preliminary results, however, shows differences between countries, ranging from 25\% in Germany to about 60\% in France.

\section{Role of MOOCs in EU Compared to U.S.}

In this section we discuss the results of Section 4 of the survey that encompasses four identical questions used in the US2013 survey. Only two of those four questions were repeated in the US2014 survey.

Figure 3 shows the response for the question "MOOCs are important for institutions to learn about online pedagogy." Figure 4 presents the results of the question "credentials for MOOC 
completion will cause confusion about higher education degrees." Figure 5 reveals the results of the question "MOOCs are a sustainable method for offering courses." Figure 6 illustrates the results of the question "how well are MOOCs meeting institution's objectives."

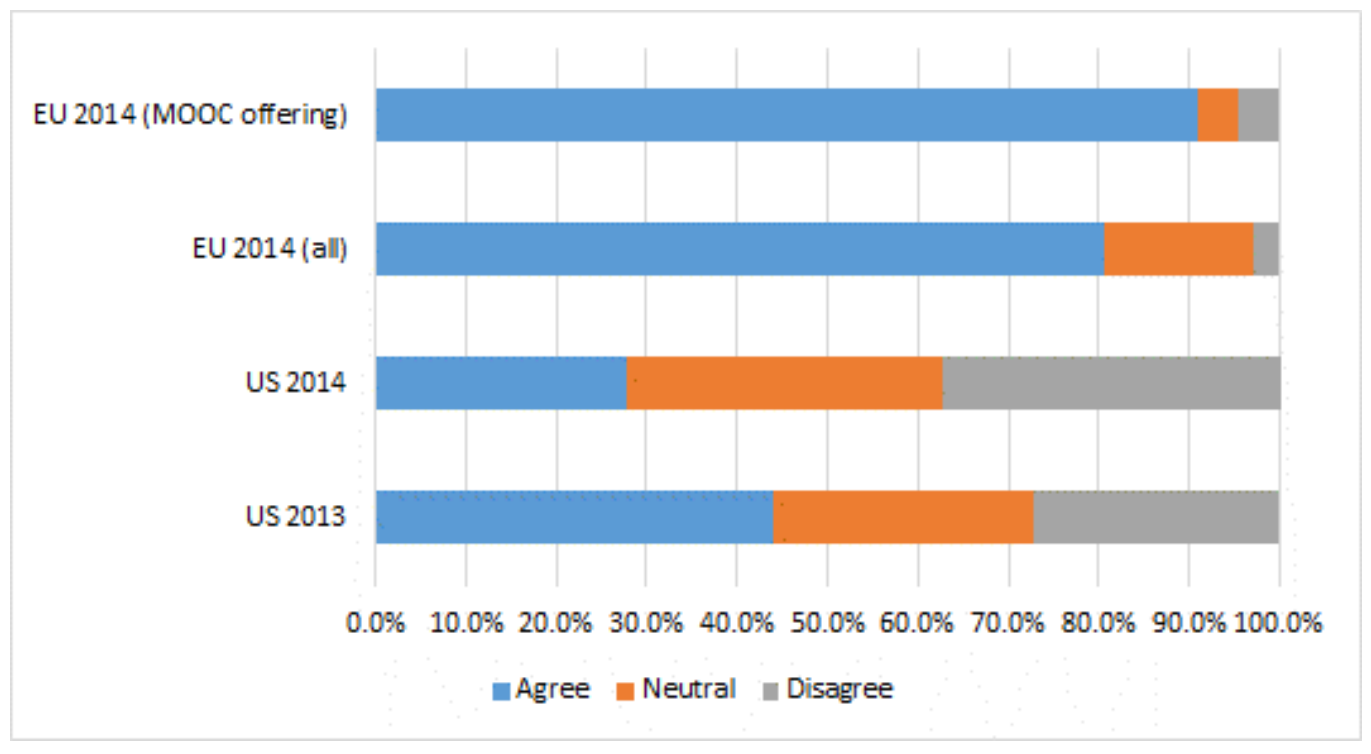

Figure 3. MOOCs are important for institutions to learn about online pedagogy.

While in the U.S. survey, the opinions are mostly neutral or disagree, in the EU version a large majority of the respondents agree that "MOOCs are important to learn about online pedagogy."

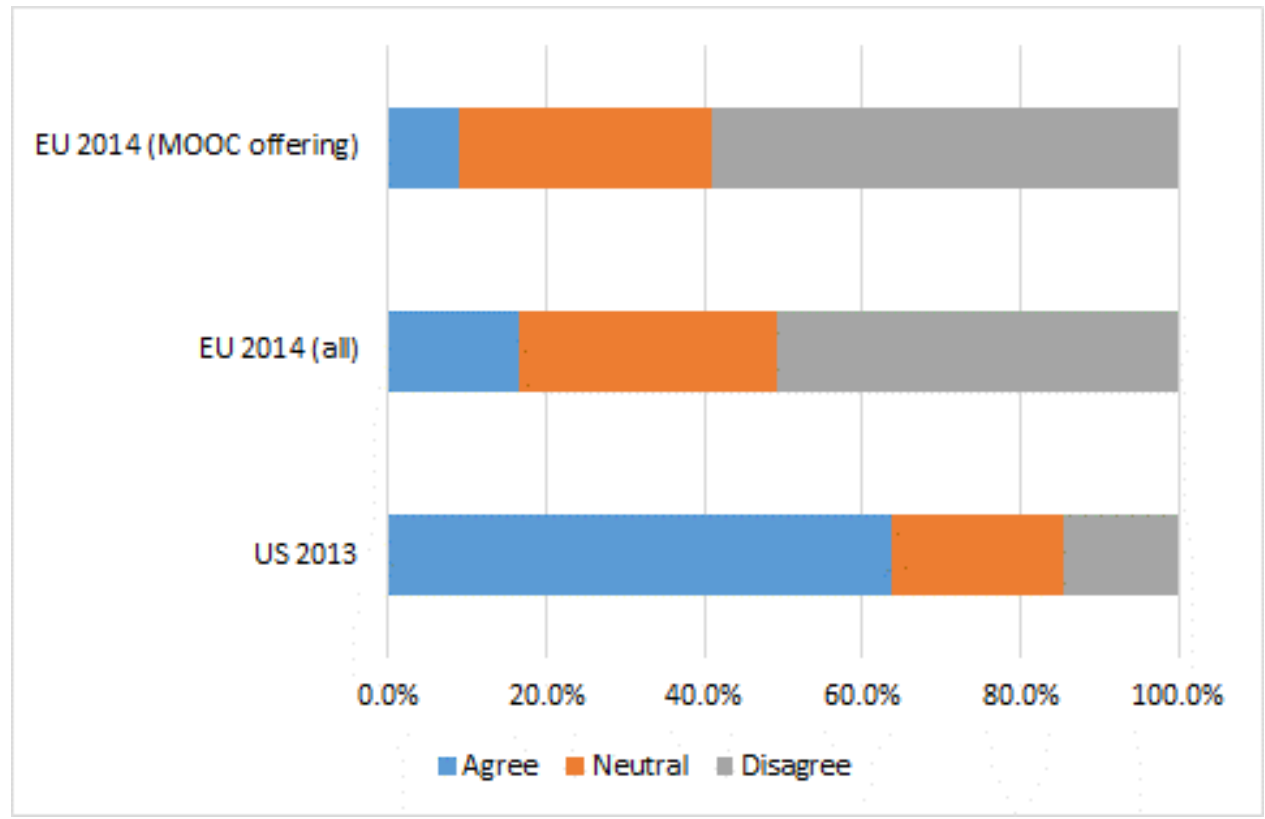


Figure 4. Credentials for MOOC completion will cause confusion about higher education degrees.

In contrast to U.S., the European HEIs seem to disagree with the statement that "Credentials for MOOC completion will cause confusion about higher education degrees."

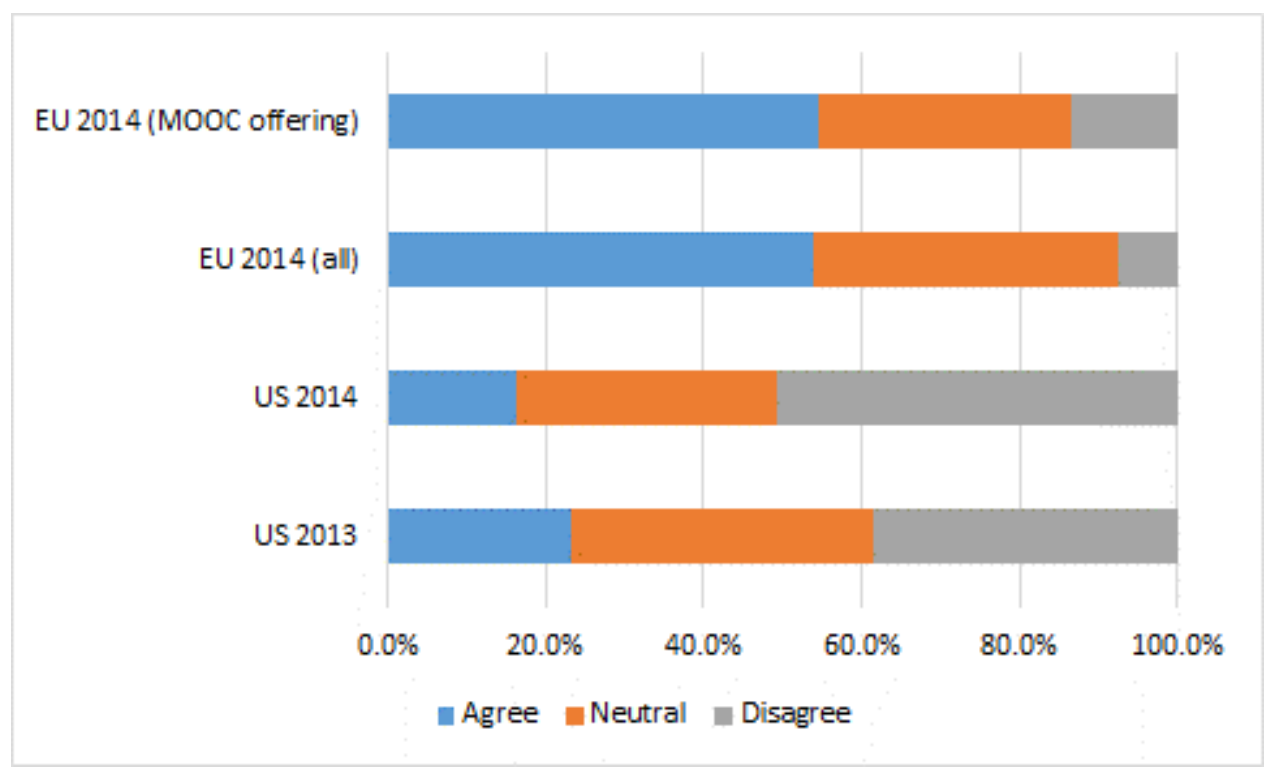

Figure 5. MOOCs are a sustainable method for offering courses.

While U.S. institutions are mostly neutral or disagree, more than half of the EU institutions agree that MOOCs are a sustainable method for offering courses. 


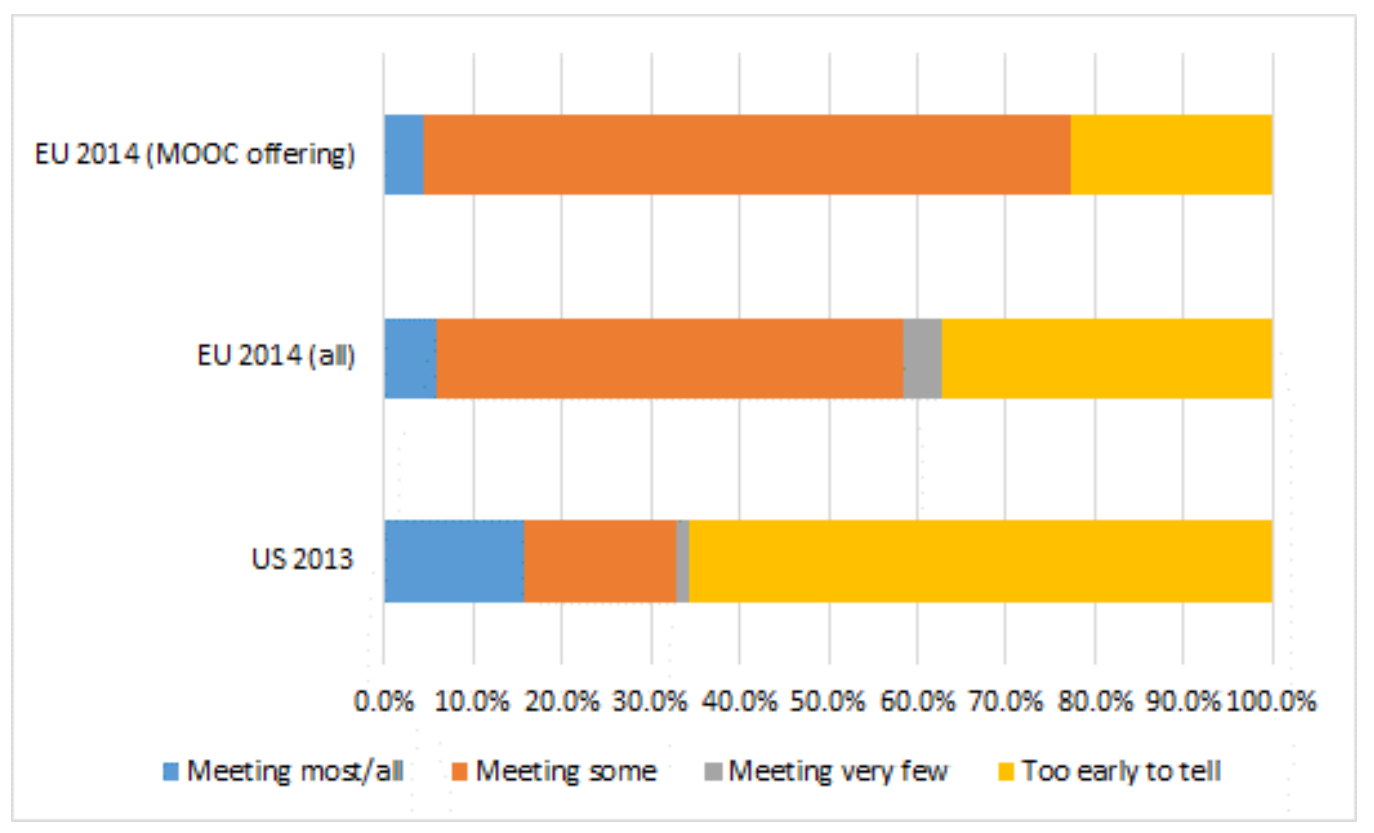

Figure 6. How well are MOOCs meeting institution's objectives?

In this study $72.7 \%$ of responded European HEIs with MOOC offer indicate that some institutions' objectives are met. The option "Too early to tell" is almost twice as big among U.S. institutions compared to the EU. This result, combined with the number of European HEIs involved in MOOCs (figure 2), indicate that MOOCs are becoming mainstream in Europe.

\section{Institutional Objectives on MOOCs}

Here we discuss sections 5 and 6 of the survey. Again several questions are identical to the U.S. survey (Allen \& Seaman, 2014). Figure 7 shows the primary objectives of the HEIs for offering a MOOC. 


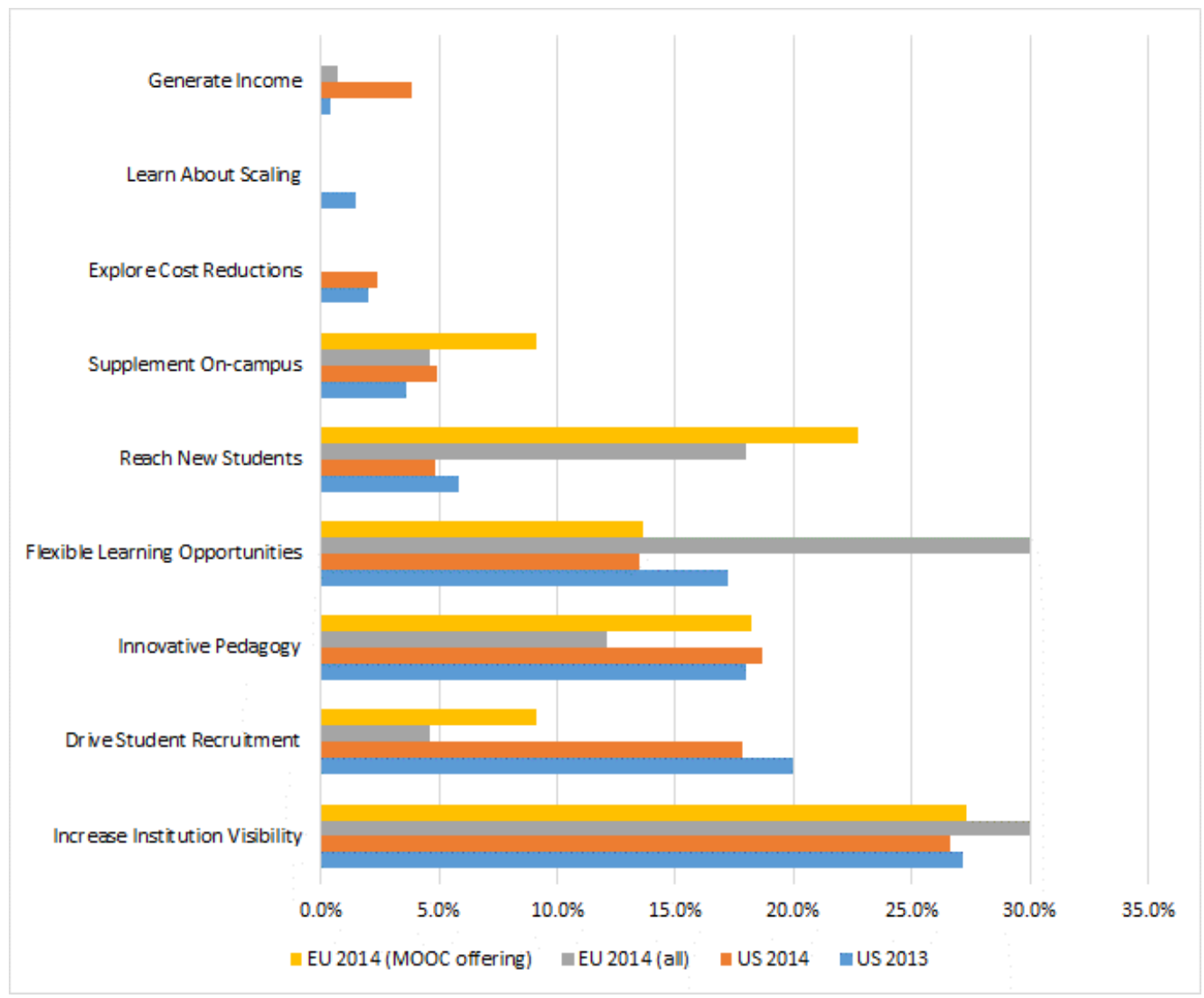

Figure 7. Primary objectives to offer a MOOC.

In all surveys, the objectives related to finance (explore cost reduction, generate income) and scalability dimensions of MOOCs are not regarded as primary objectives. Interesting is the relative low importance of "Flexible learning opportunities" with institutions that offer MOOCs in Europe compared to all responded HEIs. We also conclude that in Europe using MOOCs for student recruitment is not considered as important as in U.S., but rather to reach new students and creating flexible learning opportunities (for those new students). The latter seems consistent with the focus on MOOCs as a way of learning about online pedagogy in the EU (figure 3).

These results are partly consistent with EUA2013. They state that "International visibility is by far the most common motivation for developing MOOCs, followed by the wish to boost student recruitment" (Gaebel et al. 2014, p.54). The second motivation named in this phrase is inconsistent with EU2014, where drive student recruitment is considered a primary objective by only $4.6 \%$ of the institutions. EUA2013 also conform that only very few European institutions select "income generation," "cost reduction," and "funding opportunities" as top priority. 
Based on Allen and Seaman (2014), Hollands and Tirthali (2014) and Yuan, Powell and Olivier (2014), four main clusters were identified to further address the relative importance of different objectives (Jansen \& Schuwer, 2015). As such the following question (not part of the US surveys) was included in the EU2014 survey (exact wording):

Relative importance of the following objectives for your institution's MOOCs (or if you plan to offer a MOOC).
A. Using MOOCs for financial reasons (e.g., reduce costs, generate additional income)
B. Using MOOCs for reputation / visibility reasons (e.g., student recruitment, marketing potential / reach new student)
C. MOOCs as innovation area and online education, improve teaching)
D. Responding to the demands of learners and societies
(e.g., improve quality of on campus offering, contribute to the transition to more flexible

Each objective was again scored on a 5-point scale ranging from "Not at all relevant for my institution" to "Highly relevant for my institution."

Figure 8 illustrates the relevance per objective for institutions. In line with the results of the previous question, the figure shows that financial reasons are not the dominant objective. The other three objectives are almost equally indicated as relevant or highly relevant, with a tendency to objective B considered more relevant (55.2\% considering this highly relevant). Hollands and Tirthali (2014) found "Extending reach and access" and "Building and maintaining brand" as the two most mentioned goals. This is in line with the responses considering "Using MOOCs for reputation/visibility reasons" (objective $\mathrm{B}$, which is the comparable category for these two goals). 


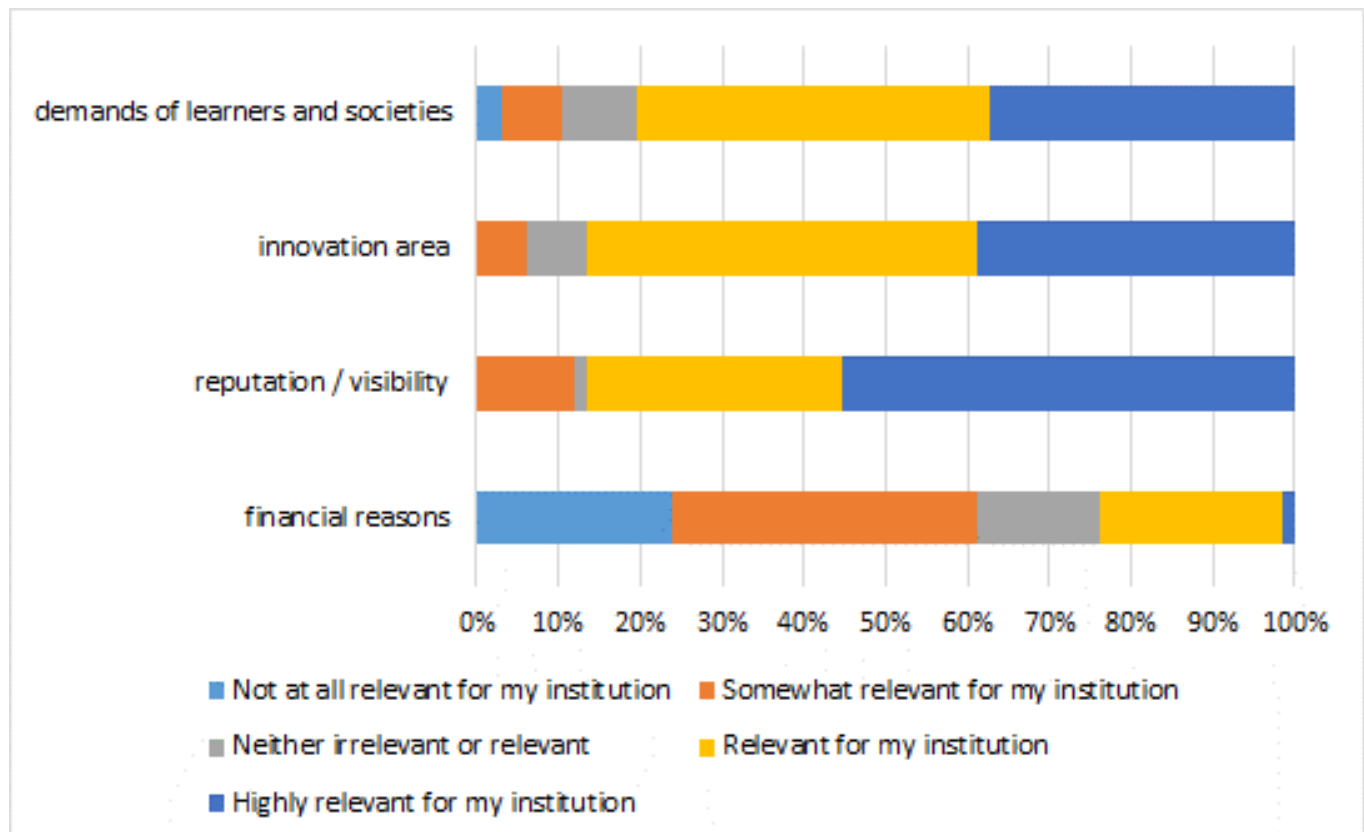

Figure 8. Relevance of four different objectives.

\section{MOOCs and Open, Online Learning}

One important flaw in all surveys (US, EUA and the current one) is the absence of a MOOC definition beforehand. The HOME project, together with other EU-funded projects, agreed to the following definition of MOOCs to prevent those projects being potentially ill-defined: "MOOCs are online courses designed for large numbers of participants, that can be accessed by anyone anywhere as long as they have an internet connection, are open to everyone without entry qualifications, and offer a full/complete course experience online for free" (Brouns et al., 2014, p.48). A more detailed argumentation behind this definition can be found at (ECO, 2014) and (OpenupEd, 2014).

However, this strict definition may not be accepted by all institutions involved in MOOCs. It has already observed that every letter in MOOC is negotiable and as such there are many different definitions of MOOCs. MOOCs can be seen as a term related to the scalability of open and online education, or perceived as political instrument and consequently should be a broadly defined concept. In the survey we asked HEIs about the relative importance of each (possible) MOOC dimensions indicated by its acronym, M-O-O-C.

\section{Massive}

The first letter in MOOCs refers to massive. A MOOC differs from other open online courses by its number of participants. To determine the importance of the "massive" dimension we included two questions in the survey (again exact wording): 
How important are the following two dimensions of a MOOC for learners/participants:

1. MOOCs must be designed for massive audiences.

2. In addition MOOCs should provide a sustainable model for massive audiences. For instance, leverage massive participation or a pedagogical model such that human efforts in all services does not increase significantly as the number of participants increases.

The responses to these two questions are shown in Figure 9, demonstrating that according to a large majority MOOCs should provide a sustainable model for the mass audience, supporting the definition of MOOC as proposed above.

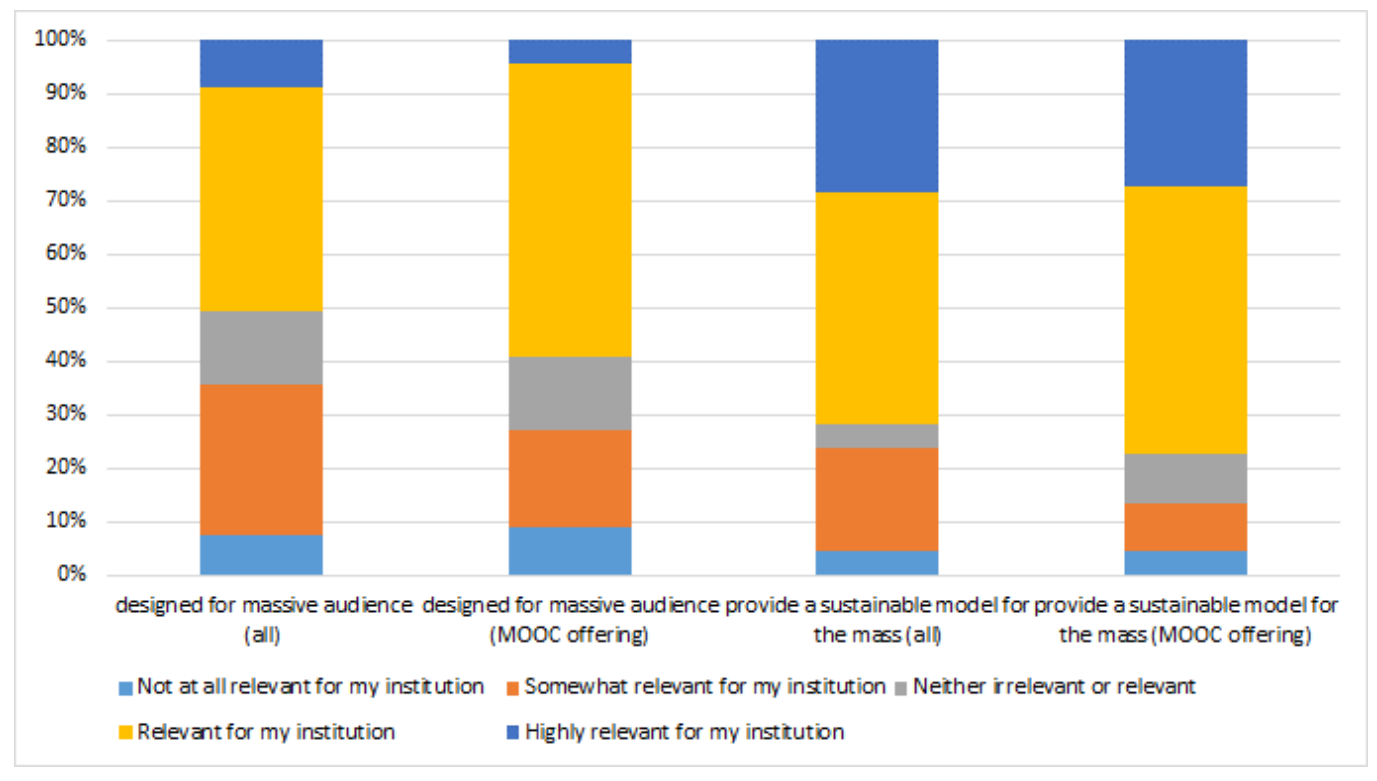

Figure 9. Importance of the massive dimension of MOOCs.

\section{Open}

The next letter in MOOCs refers to open. Open can have many interpretations (see for example Bates, 2015; Weller, 2014). To this end we included six questions (exact wording as in survey, italic is illustration as given):

How important are the following dimensions of a MOOC for learners/participants?

1. Anybody can enter the course, i.e. course is accessible to all people without limitations. This does not necessarily imply that the course can be taken without any learnt competencies or experiences. 
2. MOOCs should offer open licenses such that participants can retain - reuse - remix rework - redistribute material of the MOOC.

3. A MOOC should be for free, i.e. without any costs for participants.

4. MOOCs should NOT be offered for free by definition.

By designing for massive participation MOOCs could also have a low fee (and still be affordable).

5. In addition MOOCs offer the opportunity for participants to get (for a small fee) a formal credit as a component of an accredited curriculum.

6. Participants of a MOOC should have the freedom to choose for different kind of recognition options

MOOC participants can choose between badges earned for completion of specific activities, a credential for completion of the majority of activities and a final online test, and full certificate with ECTS credit obtained after a proctored test.

Responses are shown in Figure 10a and 10b. It shows that the majority of institutions are supporting the openness in MOOCs via open accessibility, open licensing, free costs for participants, and the freedom for participants to choose different kinds of certificates or other recognition. Next, institutions do not support the idea that MOOCs should require payment except for getting a formal credit as part of an accredited curriculum (e.g., a verified certificate, to obtain formal credits in bachelor degree of an institution).

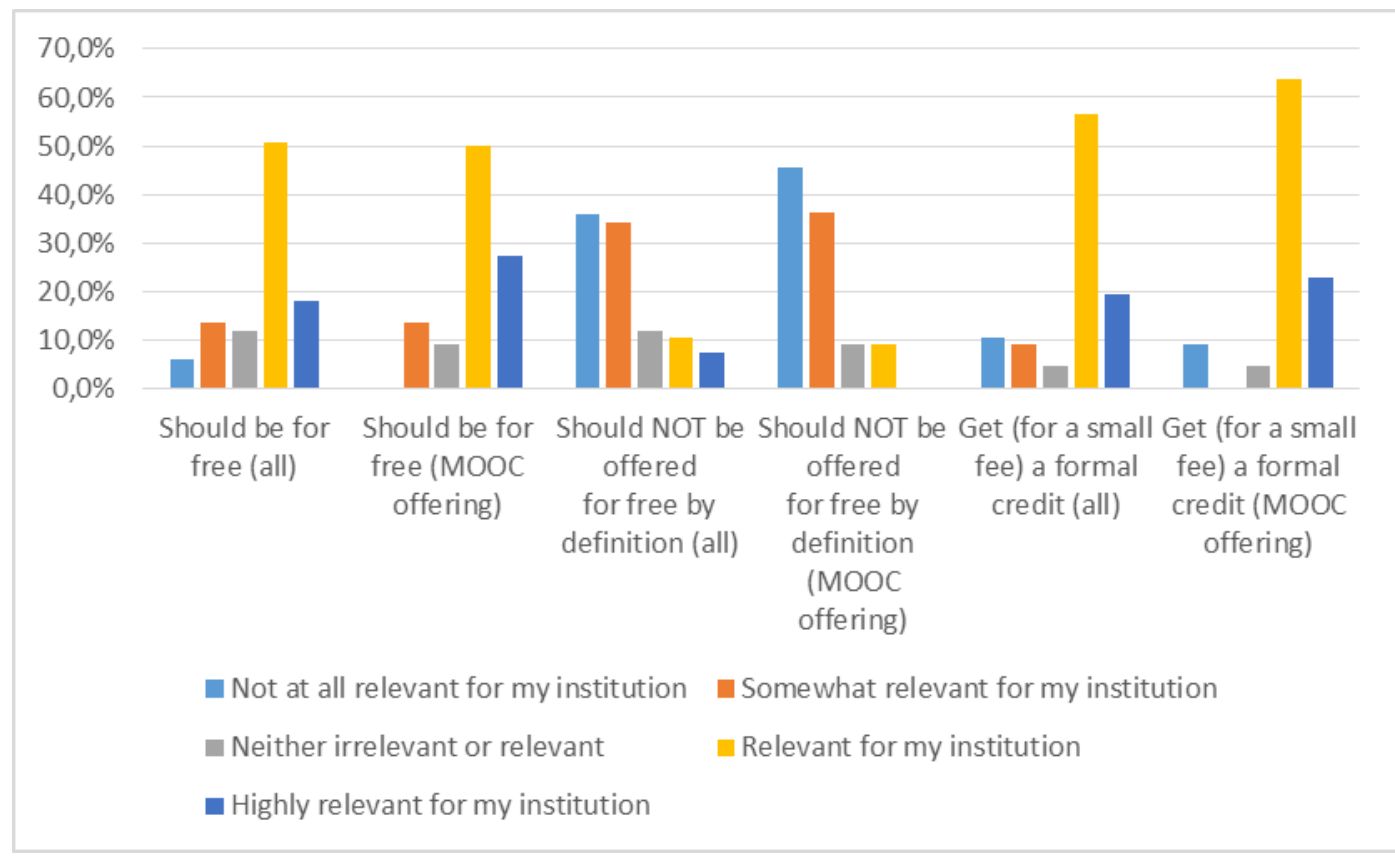

Figure 10a. The importance of the open dimension in MOOCs (dimension 3, 4 and 5) 


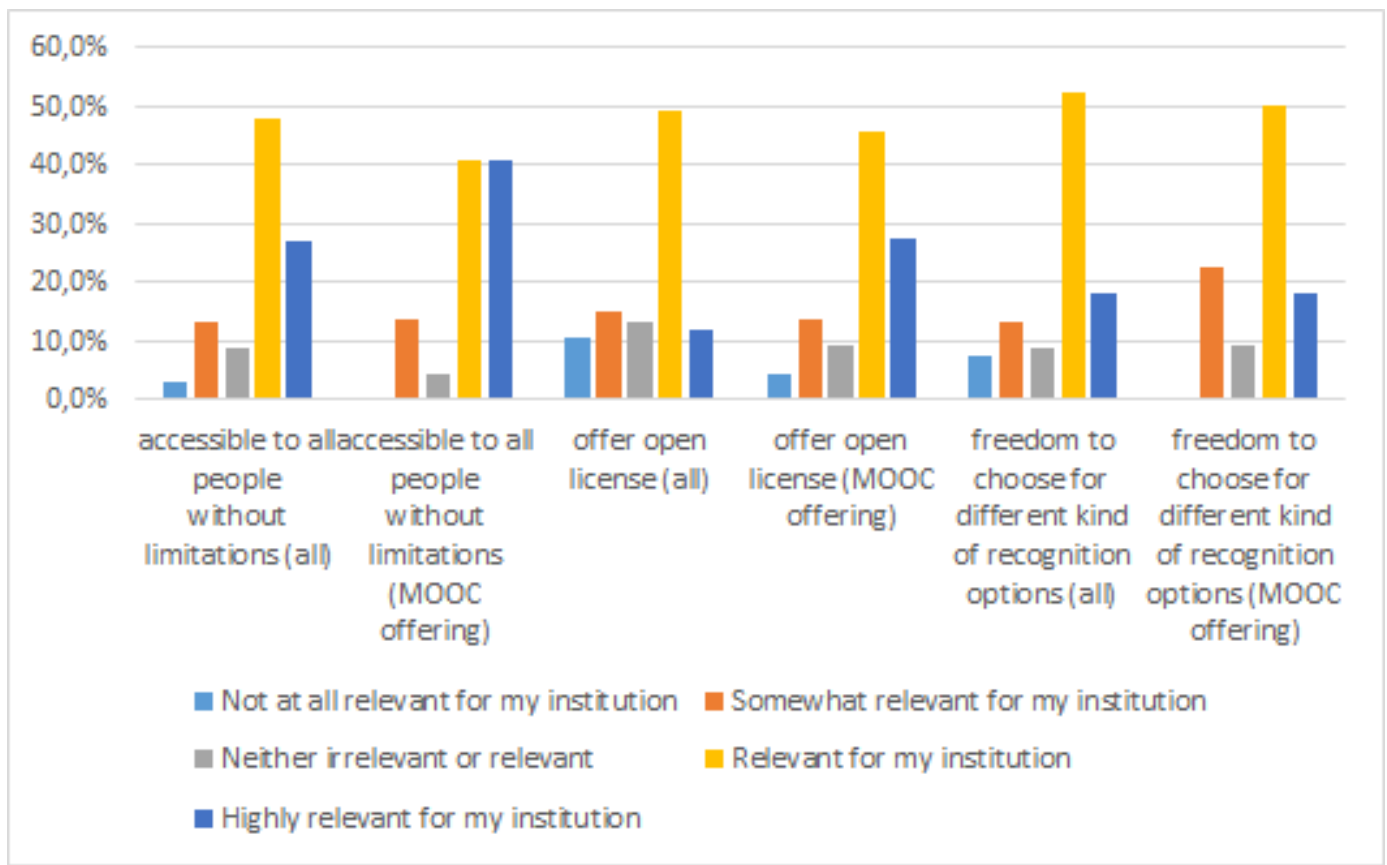

Figure 1ob. The importance of the open dimension in MOOCs (dimension 1, 2 and 6)

There is no strong support for a little fee in the MOOC definition. Therefore in our proposed definition we explicitly state that MOOCs should offer complete courses for free. Note that Selwyn, Bulfin and Pangrazio (2015) propose that MOOCs are "courses available to masses of online learners for little or no cost."

What is perhaps surprising is institutional support for open licensing as part of the MOOC 'open' dimension. Until now this has not been included as part of the definition of MOOCs in the literature or field.

\section{Online}

The third letter in the MOOC acronym refers to online. For this online dimension we included the following three questions:

How important are the following dimensions of a MOOC for the learners/participants?

1. MOOCs should offer courses completely online.

2. The final exams of a MOOC for formal credit should be offered online (with respect to quality procedures, authentication, etc.).

3. MOOCs should support off-line access for those with weak network connectivity. 


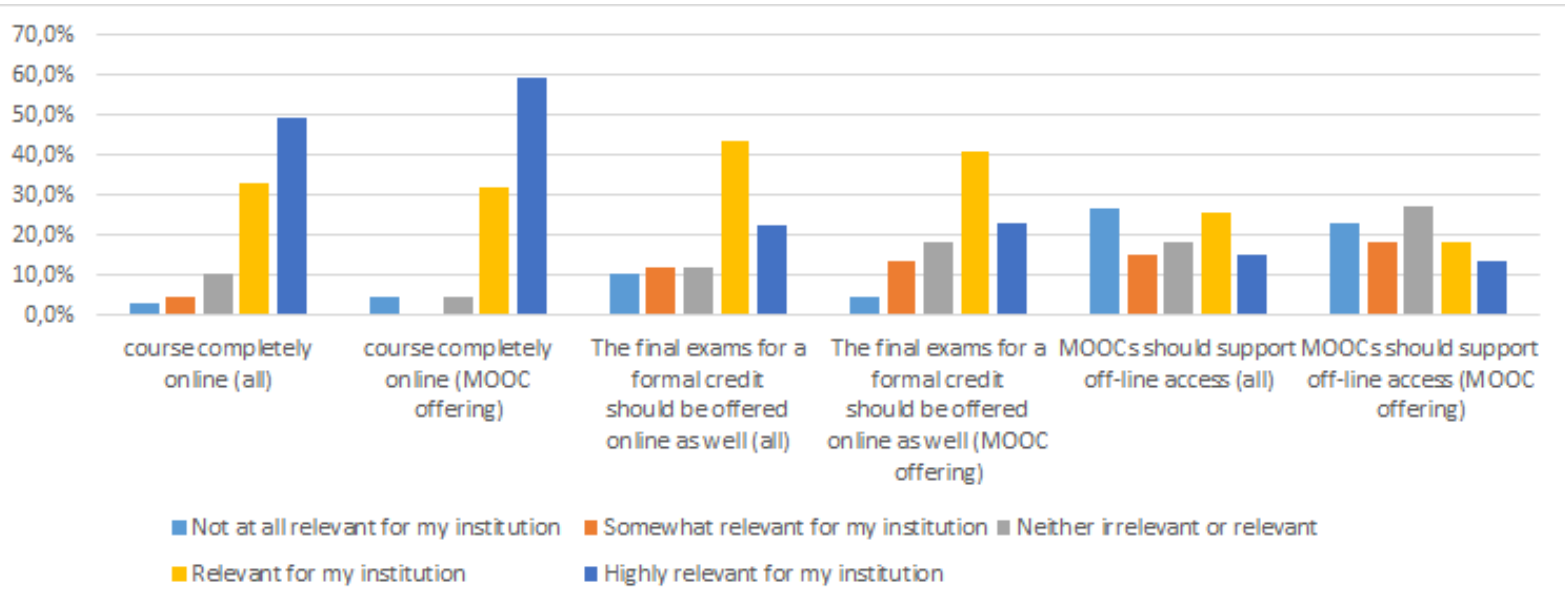

Figure 11. The importance of the online dimension in MOOCs.

Not surprisingly a large majority support that courses should be offered completely online (Figure 11). They even support the idea that exams for formal credit can be offered online. There is in general less support for the suggestion to support participants who have a weak internet connection (like for example participants in parts of the Southern hemisphere and other remote geographies).

\section{Course}

The last letter in MOOCs refers to course. Here we included the following five questions:

How important are the following dimensions of a MOOC for the learners/participants?

1. MOOCs should have fixed starting and end dates with imposed paces for every participants.

2. At least the course content of a MOOC should be accessible anytime (i.e. not only between start and end date for a scheduled course).

3. MOOC participants should also have the freedom to define their own pacing and finish whenever they want.

4. MOOCs should offer courses of best quality and as such be part of quality assurance of the institution,

5. MOOCs should be using proven modern online learning pedagogies

Figure 12 shows the response of the 67 institutions. Again a large majority supports the concept that course content of a MOOC should be accessible anytime and that the courses should be of 
best quality using proven modern online learning pedagogies. However, there seems to be no agreement that MOOCs have a fixed starting date and/or that self-paced courses can also be called MOOCs. From the definition at the beginning of this section (ECO, 2014; OpenupEd, 2014) we therefore excluded date and pace issues from being critical dimensions for a definition of MOOCs. It is open for contextual choices; i.e. MOOCs may have fixed dates or not, depending on the institution's choice for a particular course. However, this is still a subject of debate. For example, Open Education Europa (2014) excludes self-paced courses in their European MOOC Scoreboard while recently Coursera is offering self-paced MOOCs as well.

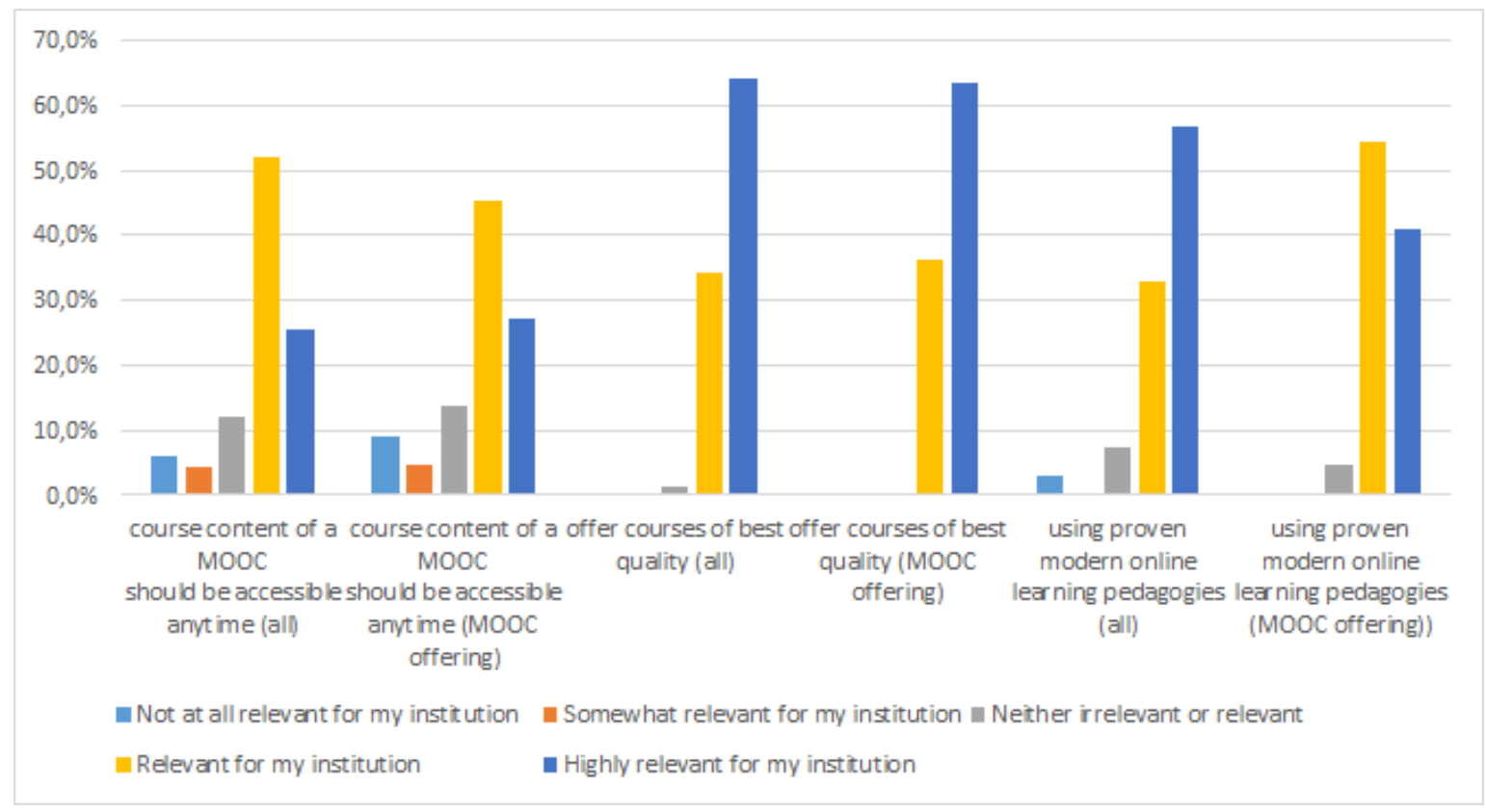

Figure 12. The importance of the course component in MOOCs.

\section{Conclusions}

This article summarises the results of the HOME project survey that depicts institutional strategies regarding MOOCs and presents a study comparing the perceptions of European HEIs with those of the U.S.

This study must be seen as a starting point to address the possible differences between HEIs in U.S. and Europe in their possible goals and the strategic choices behind the development of a MOOC. To this end we reused questions of the US surveys. Academically these might not be the best valid and reliable questions and further efforts on both continents are needed to improve those questions. In addition, comparison is hindered by different survey methods and by not defining MOOC beforehand. As such we need continuous efforts from this terminus a quo. 
The first major conclusion of this survey is that European higher education institutions are clearly confident regarding MOOC development and implementation. In fact, most institutions participating in this study plan to offer MOOCs. This interesting finding is consistent with the results of the study conducted by the EUA in which about $56 \%$ of the European institutions declared to offer a MOOC already or are planning to introduce them. We conclude that MOOC provision is set to become a mainstream trend in Europe in the next years.

As such we might conclude that the European HEIs are more broadly involved in MOOCs compared to the U.S. institutions. In the U.S. surveys, the participant HEIs are mostly neutral or disagree on the question if MOOCs are a sustainable method for offering courses, but in the EU survey more than half of the institutions agrees. While in the U.S. surveys, a large majority (66\%) states that it is too early to tell if MOOCs are meeting the institution's objective, the majority in EU version (58\%) emphasizes that MOOCs are already meeting some or most objectives. The European institutions are having a more positive attitude towards MOOCs and those offering MOOCs have positive experiences.

Two additional major findings are that the objectives related to finance and scalability dimensions of MOOCs are not seen as primary objectives for European HEIs, and student recruitment is not seen as a major goal. To the contrary, reaching new target groups and creating flexible learning opportunities seem to drive institutional strategies according to our survey responses.

Such a clear difference between US and EU perspectives needs further research. One possible reason might be related to the difference between higher educational systems. The continental European approach is related to state funding in which most institutions have equal resources and status while the more market-based US model has mixed private-public funding and provision with large differences between HEIs. This social dimension of higher education in continental Europe might be a possible explanation such that HEIs report that they already met some of their objective with MOOC provision. In addition many European HEIs can financially be involved in MOOCs, and also wants to be involved in MOOCs. Because of the high visibility of the MOOC movement attention in media, it is highly beneficial for professors to be the first one in his/her university and for an institution to be the first one in the country. Some differences between U.S. and Europe can also be explained by the presence of the ECTS framework in Europe, which provides a sound base for recognition of credentials across institutions and national borders.

\section{Acknowledgment}

This research is conducted as part of the European Union-funded project HOME - Higher education Online: MOOCs the European way (Ref. 543516-LLP-1-2013-1-NL-KA3-KA3NW). We would like to thank all project partners for their contributions. However, sole responsibility for

This work is licensed under a $\underline{\text { Creative Commons Attribution } 4.0 \text { International License. }}$ 
this article lies with the authors, and both the Commission and the HOME partners are not responsible for any use that may be made of the information contained therein.

\section{References}

Allen, I.E, \& Seaman, J. (2014). Grade change: Tracking online education in the United States. Babson Survey Research Group Report. Retrieved from http://www.onlinelearningsurvey.com/reports/gradechange.pdf

Allen, E., \& Seaman, J. (2015). Grade level: Tracking online education in the United States. Babson Survey Research Group Report. Retrieved from: http://www.onlinelearningsurvey.com/reports/gradelevel.pdf

Bates, T. (2015). What do we mean by 'open' in education? Retrieved from: http://www.tonybates.ca/2015/02/16/what-do-we-mean-by-open-ineducation/\#sthash.7wk8lvjE.dpuf

Brouns, F., Mota, J., Morgado, L., Jansen, D., Fano, S., Silva, A., \& Teixeira, A. (2014, 27-28 October). A networked learning framework for effective MOOC design: The ECO project approach. In A. M. Teixeira \& A. Szücs (Eds.), 8th EDEN Research Workshop. Challenges for Research into Open \& Distance Learning: Doing Things Better: Doing Better Things. Oxford, United Kingdom Budapest, Hungary: EDEN.

Cormier, D. (2008, October 2). The CCKo8 MOOC - Connectivism course, 1/4 way. [Dave's Educational Blog]. Retrieved from http://davecormier.com/edblog/2008/10/02/theccko8-mooc-connectivism-course-14-way/

ECO (2014). E-Learning, communication and open data: Massive, mobile, ubiquitous and open learning. Retrieved from http://ecolearning.eu/wpcontent/uploads/2014/06/ECO D2.2 Instructional design and scenarios v1.0.pdf

European Commission (2013). Opening up education: Innovative teaching and learning for all through new technologies and open educational resources. Brussels, Belgium. Retrieved from http://eur-lex.europa.eu/legalcontent/EN/TXT/PDF/?uri=CELEX:52013DC0654\&from=EN

Gaebel, M., Kupriyanova, V., Morais, R., \& Colucci, E. (2014). E-learning in European higher education institutions: Results of a mapping survey conducted in October-December 2013. Retrieved from http://www.eua.be/Libraries/Publication/elearning survey.sflb.ashx

This work is licensed under a Creative Commons Attribution 4.0 International License. 
Hollands, F., \& Tirthali, D. (2014). Why do institutions offer MOOCs? Online Learning, 18(3). Retrieved from http://olj.onlinelearningconsortium.org/index.php/jaln/article/view/464

HOME (2014). Higher education Online: MOOCs the European way. Retrieved from http://home.eadtu.eu/

Jansen, D., \& Schuwer, R. (2015). Institutional MOOC strategies in Europe. Status report based on a mapping survey conducted in October - December 2014. EADTU. Retrieved from http://www.eadtu.eu/documents/Publications/OEenM/Institutional MOOC strategies in Europe.pdf

JRC-IPTS (2015). How are higher education institutions dealing with openness? A survey of practices, beliefs and strategies in five European countries. JRC Institute for Prospective Technological Studies, European Commission. To be published autumn 2015.

OpenupEd (2014). Definition massive open online courses (MOOCs). Retrieved from http://www.openuped.eu/images/docs/Definition Massive Open Online Courses.pdf

Open Education Europa (2015). European MOOCs Scoreboard. Retrieved from http://www.openeducationeuropa.eu/nl/european_scoreboard_moocs

Selwyn, N., Bulfin, S., \& Pangrazio, L. (2015). Massive open online change? Exploring the discursive construction of the 'MOOC' in newspapers. Higher Education Quarterly, 1-18.

Weller, M. (2014). Battle for Open: How openness won and why it doesn't feel like victory. London: Ubiquity Press. Retrieved from http://dx.doi.org/10.5334/bam

Wikipedia (2015). Massive open online course. Retrieved from http://en.wikipedia.org/wiki/Massive open online course

Yuan, L., Powell, S., \& Olivier, B. (2014). Beyond MOOCs: Sustainable online learning in institutions. CETIS, Bolton. Retrieved from http://publications.cetis.ac.uk/2014/898

\section{Athabasca University}

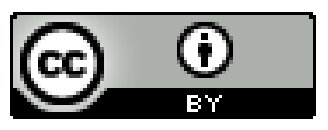

